\title{
Análise da forma e tamanho de grânulos de amidos de diferentes fontes botânicas
} Analysis of the shape and size of starch grains from different botanical species

\author{
Magali LEONEL ${ }^{1 *}$
}

\begin{abstract}
Resumo
Neste trabalho, objetivou-se avaliar a forma e tamanho de grânulos de amido de diferentes fontes botânicas, visando fornecer informações que contribuam para aplicabilidade destas como matérias-primas amiláceas. As féculas foram obtidas a partir do processamento das tuberosas em planta piloto de extração. Para a análise da forma dos grânulos utilizou-se o microscópio eletrônico de varredura, com as amostras diluídas em álcool etílico e metalizadas com ouro. A análise do tamanho dos grânulos foi realizada em microscópio ótico, sendo as amostras diluídas em solução de água e glicerina. Foram realizadas 500 determinações das medidas de tamanho (diâmetro menor, diâmetro maior e diferenças entre diâmetros) por fonte botânica. Os resultados obtidos mostraram diferentes formas para os grânulos de amidos e das tuberosas estudadas. Os grânulos de amido de menor tamanho foram os de taioba (Xanthosoma sp.) 12,87 $\mu$ m, e os de maior tamanho os de biri (Canna edulis) 59,61 $\mu \mathrm{m}$. Observou-se distribuição bastante regular para os grânulos de amido de ahipa (Pachyrhizus ahipa).

Palavras-chave: amido; raízes; microscopia.
\end{abstract}

\begin{abstract}
An analysis was made of the shape and size of starch grains from different botanical species, aiming to improve the potential applicability of these species as starch raw materials. The starches were obtained from the processing of tubers in a pilot extraction plant. The shape of the starch grains was analyzed by scanning electron microscopy (SEM), to which end the samples were mounted on SEM stubs and coated with gold. The size of the starch grains was determined by optical microscopy, for which the samples were diluted in a water and glycerin solution. The sizes of 500 grains of each botanical species were measured to determine the largest and smallest diameters and the difference between diameters. The results revealed different starch grain shapes and sizes, with Xanthosoma sp showing the smallest ( $12.87 \mu \mathrm{m})$ and Canna edulis the largest grain size $(56.61 \mu \mathrm{m})$. The yam bean tuber Pachyrhizus ahipa showed the most uniform starch grain distribution.

Keywords: starch; roots; microscopy.
\end{abstract}

\section{Introdução}

As indústrias de alimentos e os produtores agrícolas estão interessados na identificação e no desenvolvimento de espécies que produzam amidos nativos com características especiais. Estes amidos poderiam substituir amidos modificados quimicamente ou abrir novos mercados para amidos ${ }^{1}$.

O tamanho e a forma de grânulos de amido estão entre os fatores de importância na determinação de usos potenciais de amidos. Por exemplo, grânulos pequenos $(2,0 \mu \mathrm{m})$ podem ser usados como substitutos de gordura devido ao tamanho ser semelhante ao dos lipídeos. Outras aplicações, nas quais o tamanho dos grânulos é importante, é a produção de filmes plásticos biodegradáveis e de papéis para fax.

O grânulo de amido tem sido submetido a estudos sobre sua estrutura deste a invenção da microscopia. A microscopia aparece como uma ferramenta importante na elucidação de diversas questões sobre caracterização de grânulos de amido. A escolha da técnica e do microscópio para uma visualização de alta resolução da estrutura dos grânulos de amido, é dependente do tipo de informação requerida, ou seja, superfície, ou estrutura interna. Informações sobre a superfície dos grânulos podem ser conseguidas tanto com a microscopia eletrônica de varredura (SEM) ou microscopia de força atômica (AFM).

Recebido para publicação em 29/8/2006

Aceito para publicação em 23/4/2007 (001830)

Centro de Raízes e Amidos Tropicais, Universidade Estadual Paulista - UNESP,

Fazenda Experimental Lageado, s/n, CP 237, CEP 18603-970,

Botucatu - SP, Brasil

E-mail: mleonel@fca.unesp.br

* A quem a correspondência deve ser enviada
Informações sobre estrutura interna requerem o uso da microscopia eletrônica de transmissão (TEM) ${ }^{11}$.

Na determinação do tamanho dos grânulos, têm sido aplicados métodos microscópicos, principalmente utilizando a microscopia eletrônica de varredura e também outras metodologias como técnicas de sedimentação, contador Coulter e o uso de contadores de partículas utilizando feixes de raios laser (difração de raio laser). O uso da microscopia apresenta algumas desvantagens como a irregularidade e a diversidade das formas dos grânulos e também a dificuldade da amostragem na distribuição de tamanho de grânulos. Já a contagem em laser, técnica bastante usada, tem como base que os grânulos são esféricos, o que faz com que esta técnica não seja apropriada para grânulos de amido de formas diferentes, como relata SINGH e SINGH ${ }^{28}$, para batata, os quais são oblongos, ovalados e cuboidais.

Atualmente vêm sendo utilizados sistemas de análise de imagem, que unem o microscópio óptico ao computador e apresentam como princípio a separação de imagens dentro de áreas pretas e brancas contra um segundo plano. Esta metodologia apresenta a possibilidade da união de imagens geradas no microscópio serem avaliadas com precisão, contando com a versatilidade dos sistemas de análise. O uso destes sistemas tem sido descrito em pesquisas na área de amido, principalmente em estudos de forma e tamanho de grânulos, alterações químicas ou físicas e controle de qualidade de produtos ${ }^{2,29,31}$.

O tamanho e a forma dos grânulos de amido variam com a espécie, e a distribuição de tamanho varia com o estádio de desenvolvimento da planta e forma de tuberização. Outro 
parâmetro interessante é a regularidade na forma, ou seja, diferença entre diâmetros, parâmetro que indica regularidade do tamanho, baixa variabilidade das medidas, característica desejável para papéis químicos como os usados para cópias e fax ${ }^{26}$.

LEONEL et al. ${ }^{16,17}$, utilizando a microscopia eletrônica de varredura para análise da forma e tamanho de grânulos de amido de araruta (Maranta arundinacea) e biri (Canna edulis), observaram grânulos das formas ovalada e circular com espessura visível e diâmetro maior médio variável de 9 a $65 \mu \mathrm{m}$ para amido de biri. Para amido de araruta observaram grânulos circulares e ovalados com diâmetro maior médio de 9 a $42 \mu \mathrm{m}$.

SINGH e SINGH ${ }^{28}$ analisaram a forma e tamanho de grânulos de amido de cultivares de batata (Solanum tuberosum), utilizando a microscopia eletrônica de varredura (SEM), e observaram diferenças significativas para estes parâmetros entre as cultivares. Quanto à forma, esta variou de oval para regular ou cuboidal, com diâmetros médios variáveis de 15-20 $\mu \mathrm{m}$ e 20-45 $\mu \mathrm{m}$, respectivamente, para grânulos pequenos e grandes.

NODA et al. ${ }^{21}$ estudaram o tamanho de grânulos de amido de duas cultivares de batata-doce extraídos de diferentes zonas de tecido da raiz. Para o estudo foi utilizado sistema de análise de imagem (Excel-II, Nippon Avionics Co.) conectado a microscópio ótico (Microphot-FXA, Nikon Co.), realizando 1200 determinações de tamanho. O tamanho dos grânulos de amido variou de 20-40 $\mu \mathrm{m}$, sendo observadas curvas de distribuição semelhantes para as duas cultivares, não ocorrendo diferenças significativas entre as camadas. Esta observação evidencia que a forma de tuberização da raiz é um fator influente na distribuição de tamanho, ou seja, nas raízes em que o processo de tuberização envolve câmbio central e periférico a tendência é de uma distribuição de tamanho mais homogênea.

Este fato foi observado por MILANEZ ${ }^{20}$ que, estudando o desenvolvimento de plantas de Pachyrhizus ahipa, observou que o processo de tuberização da raiz principal do ahipa envolve não somente a atividade de um câmbio vascular típico, mas também, a atividade de câmbios assessórios distribuídos por todo o órgão. Por essa razão, não se observa um gradiente de desenvolvimento dos tecidos, o que propicia a ocorrência de distribuição de tamanho de grânulos de amido mais homogênea.

SRIROTH et al. ${ }^{29}$, estudando a influência do tempo de colheita em quatro cultivares comerciais de mandioca na Tailândia sobre a estrutura dos grânulos de amido, observaram através da análise de tamanho de grânulos de amido, utilizando sistema de análise de imagem (Carl Zeiss, KS 400 v2) acoplado a microscópio óptico (Axiophol 2 Zeiss), que a distribuição de tamanho dos grânulos foi afetada pela idade da raiz, ocorrendo uma mudança gradativa de uma distribuição normal para bimodal, ou seja, com dois picos representando faixas distintas de tamanho de grânulos de amido.

Estudos determinam que as propriedades térmicas de amidos estão estreitamente relacionadas com o tamanho e a distribuição de tamanho dos grânulos de amido ${ }^{17}$. CAMPBELL et al. ${ }^{5}$ observaram correlação positiva de alta significância entre o tamanho dos grânulos e as propriedades térmicas (DSC) de amido de 35 cultivares de milho (tropical e subtropical).

Diante da importância do conhecimento da forma e tamanho dos grânulos de amido para a determinação de aplicações potenciais, neste trabalho objetivou-se avaliar a forma e tamanho de grânulos de amido de diferentes fontes botânicas, utilizando a microscopia eletrônica de varredura (SEM) e a microscopia ótica com sistema de análise de imagem, visando fornecer informações úteis para a aplicabilidade desses amidos.

\section{Material e métodos}

\subsection{Obtenção das féculas}

As fontes botânicas foram cultivadas no Campo Experimental do CERAT/UNESP, em Botucatu - SP. O clima da região, de acordo com a classificação Koeppen, é definido como Csa ou temperado chuvoso, úmido e com verões quentes, precipitação média anual de $1517 \mathrm{~mm}$ e a temperatura média anual de $20,6{ }^{\circ} \mathrm{C}$. O solo é Latossolo roxo destrófico A moderado, latitude $22^{\circ} 52^{\prime} 47^{\prime \prime} \mathrm{S}$, longitude $48^{\circ} 25^{\prime} 12^{\prime \prime} \mathrm{W}$, altitude $810 \mathrm{~m}$. A Tabela 1 mostra a época de plantio e colheita das tuberosas amiláceas.

Tabela 1. Épocas de plantio e colheita das espécies botânicas analisadas.

\begin{tabular}{lll}
\hline \multicolumn{1}{c}{ Tuberosas amiláceas } & Plantio & Colheita \\
\hline Açafrão (Curcuma longa) & Novembro & Julho \\
Ahipa (Pachyrhizus ahipa) & Outubro & Julho \\
Araruta (Maranta arundinacea) & Setembro & Agosto \\
Batata doce (Ipomoea batatas) & Outubro & Maio \\
Biri (Canna edulis) & Outubro & Julho \\
Gengibre (Zingiber officinale) & Dezembro & Julho \\
Mandioca (Manihot esculenta) & Setembro & Setembro \\
Mandioquinha-salsa (Arracacia & Abril & Abril \\
xanthorrhiza) & & \\
Taioba (Xanthosoma sp) & Novembro & Outubro \\
Taro (Colocasia esculenta) & Outubro & Junho \\
Zedoária (Curcuma zedoaria) & Dezembro & Setembro \\
\hline
\end{tabular}

Para a mandioca, foi cultivada a cultivar Branca de Santa Catarina; para a batata-doce, a cultivar Princesa do CNPHBrasília - DF; para a mandioquinha-salsa, a Senador Amaral da EMBRAPA; e para o gengibre, a cultivar Caipira. Para as demais tuberosas não foram identificadas as cultivares. A batata, de cultivar Monalisa, foi adquirida direto com o produtor.

As féculas foram obtidas a partir do processamento das matérias-primas no Laboratório Piloto do CERAT. A Figura 1 mostra as etapas do processo de extração das féculas.

\subsection{Análise da forma e tamanho dos grânulos de amido}

Para a análise da forma e tamanho dos grânulos de amido das diferentes fontes botânicas, utilizou-se a microscopia eletrônica de varredura e a microscopia ótica. 
Na análise dos amidos em microscópio eletrônico de varredura, as amostras foram diluídas em álcool etílico 100\% $\left(1 / 10\right.$ p.v $\left.{ }^{-1}\right)$ e colocadas duas gotas nos "stubs". Depois deste procedimento, as amostras foram cobertas com $10 \mathrm{~mm}$ de ouro metalizador (MED-010 da Balzers) e analisadas em Microscópio Eletrônico de Varredura (SEM 515 Philips), sob tensão de $15 \mathrm{kV}$ ou $20 \mathrm{kV}$.

Para a determinação da distribuição dos grânulos de amido quanto ao diâmetro maior e menor, foi utilizado o Sistema de Análise de Imagem KS 300 da ZEISS. As amostras de fécula foram coletadas com um fio de platina e misturadas sobre lâminas de vidro em duas gotas de solução de água e glicerina (50\%), sendo cobertas por lamínula. Preparadas as lâminas, estas foram observadas em microscópio óptico (AXIOSKOP II - ZEISS) e as imagens selecionadas foram analisadas pelo sistema. Os parâmetros avaliados foram: forma, diâmetro maior e diâmetro menor $(\mu \mathrm{m})$. Foram feitas cinco lâminas por fonte botânica e cem medidas de tamanho de grânulos de amido por lâmina, totalizando quinhentas determinações por fonte ${ }^{30}$.

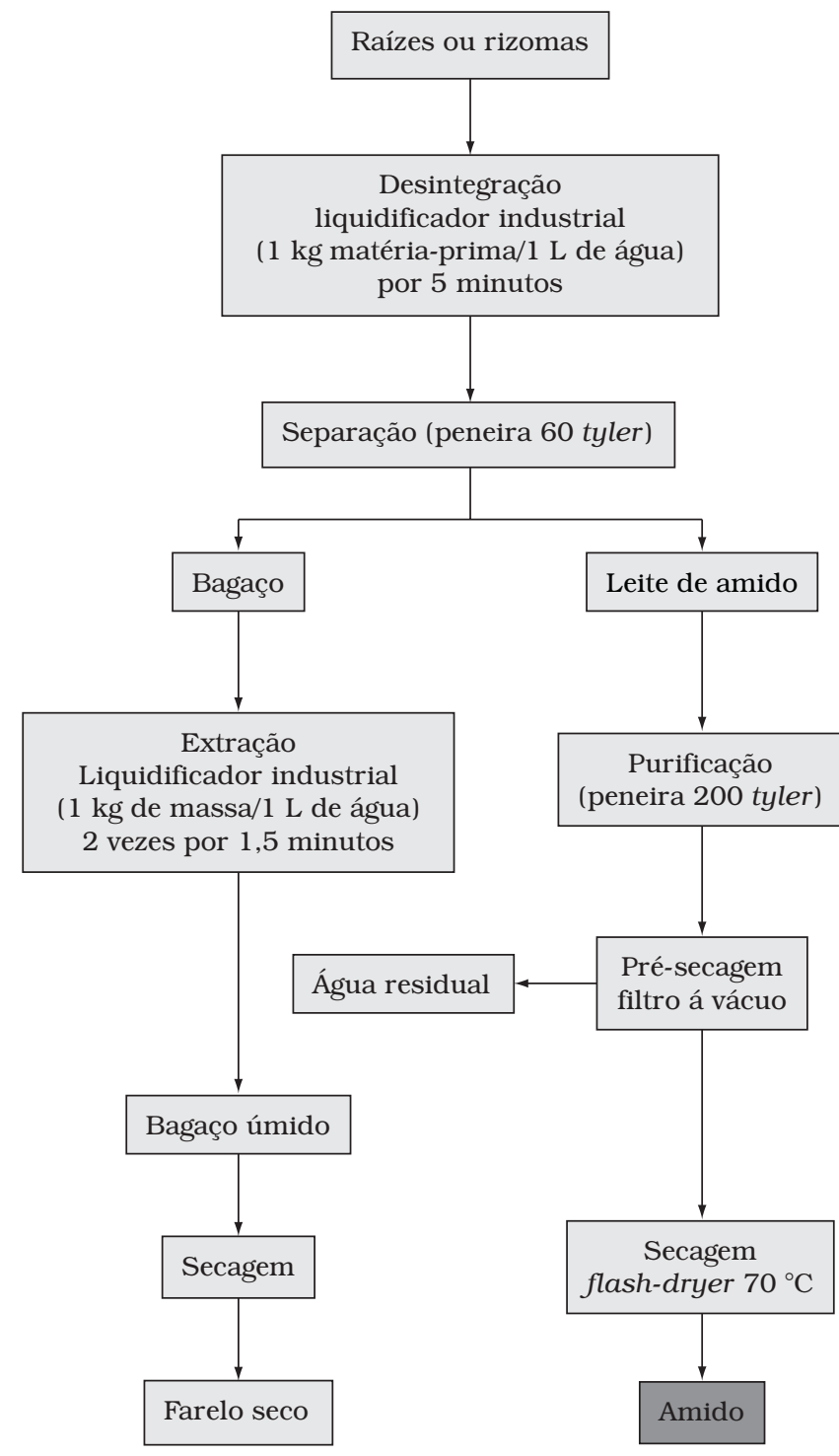

Figura 1. Fluxograma do processo de obtenção dos amidos.

\section{Resultados e discussão}

Os resultados obtidos nas análises de forma e tamanho de grânulos de amido das diferentes tuberosas amiláceas estão apresentados na Tabela 2 e nas Figuras de 2 a 12 . Os resultados obtidos mostraram diferenças significativas quanto ao tamanho para as fontes botânicas, sendo o maior tamanho (diâmetro maior médio) observado nos amidos de biri $(59,61 \mu \mathrm{m})$ e o menor nos grânulos de amido de taioba $(12,87 \mu \mathrm{m})$. Os grânulos de amido de ahipa, batata-doce e mandioquinha-salsa apresentam as mesmas formas e não ocorreu diferença significativa entre estes para as análises de tamanho.

Já quanto à diferença entre diâmetros, parâmetro que indica regularidade do tamanho, ou seja, baixa variabilidade das medidas, característica desejável para papéis químicos como os usados para cópias e fax ${ }^{26}$, a análise mostrou a menor diferença relativa (\% do diâmetro maior) para o amido de mandioca. Com relação à forma dos grânulos, diferenciam-se os grânulos de amido de açafrão e zedoária (C. longa e $C$. zedoaria) que apresentaram forma triangular achatada, sendo possível a visualização da espessura. Os amidos de biri e gengibre também apresentaram espessura visível.

A observação microscópica dos grânulos de amido de açafrão mostrou grânulos de forma triangular achatada com diferentes tamanhos ( 10 a $48 \mu \mathrm{m}$ ), com uma maior porcentagem de grânulos na faixa de $22-27 \mu \mathrm{m}$ de diâmetro maior. Devido à forma triangular a diferença entre diâmetros foi elevada (Figura 2).

O açafrão não tem sido utilizado pela indústria de amido no Brasil, porque a extração da fécula é considerada uma utilização secundária, sendo os rizomas usados apenas para obtenção de corante e, em pequenas proporções, uso direto na culinária. Os produtos principais do açafrão são a curcumina e o óleo essencial os quais são usados como condimento, corante natural, e aplicações farmacológicas ${ }^{14}$. Contudo, faz-se interessante a possibilidade de aproveitamento do resíduo da extração de óleos essenciais e corantes como matéria-prima para obtenção do amido.

A análise microscópica dos grânulos de amido de ahipa mostrou formas circular e poliédrica para os grânulos e tamanhos variáveis, sendo observada uma distribuição bastante homogênea de tamanho, com predomínio de grânulos na faixa de 15 a $20 \mu \mathrm{m}$ (Figura 3).

FORSTHY et al. ${ }^{10}$, analisando tamanho de grânulos de amido de ahipa cultivados por 7 meses, observaram faixa de distribuição de 5 a $35 \mu \mathrm{m}$.

MILANEZ ${ }^{19}$ constatou que o processo de tuberização da raiz principal de ahipa envolve não somente a atividade de um câmbio vascular típico, mas também, a atividade de câmbios acessórios distribuídos por todo o órgão. Por esta razão, não se observa um gradiente de desenvolvimento dos tecidos, o que propicia a ocorrência de distribuição de tamanho de grânulos de amido mais homogênea.

A extração do amido de araruta é feita em caráter doméstico e artesanal, sendo utilizado no preparo de confeitos e panificação ${ }^{21}$. A análise de tamanho de grânulos de amido 
Tabela 2. Forma e tamanho de grânulos de amido das tuberosas amiláceas.

\begin{tabular}{|c|c|c|c|c|c|c|c|}
\hline \multirow[t]{2}{*}{ Tuberosas } & \multirow[t]{2}{*}{ Formas } & \multicolumn{2}{|c|}{ Diâmetro menor ( $\mu \mathrm{m})$} & \multicolumn{2}{|c|}{ Diâmetro maior $(\mu \mathrm{m})$} & \multicolumn{2}{|c|}{ Diferença diâmetros $(\mu \mathrm{m})$} \\
\hline & & Média* & Desvio & Média & Desvio & Média & Desvio \\
\hline Açafrão (Curcuma longa) & Triangular achatada & $18,99^{\text {de }}$ & 1,04 & $26,10^{c}$ & 1,72 & $7,11^{\mathrm{bc}}$ & 1,04 \\
\hline Ahipa (Pachyrhizus ahipa) & Circular, poliédrica & $15,65^{\mathrm{f}}$ & 1,59 & $18,58^{\mathrm{d}}$ & 1,92 & $2,93^{\mathrm{d}}$ & 0,65 \\
\hline Araruta (Maranta arundinacea) & Circular, oval & $22,05^{\mathrm{c}}$ & 1,15 & $29,54^{c}$ & 1,59 & $7,49^{\mathrm{bc}}$ & 0,53 \\
\hline Batata-doce (Ipomoea batatas) & Circular, poliédrica & $16,10^{\mathrm{ef}}$ & 0,86 & $19,40^{\mathrm{d}}$ & 1,76 & $3,30^{\mathrm{d}}$ & 0,35 \\
\hline Batata (Solanum tuberosum) & Circular, oval & $30,51^{\mathrm{b}}$ & 1,56 & $39,50^{\mathrm{b}}$ & 2,42 & $8,59^{\mathrm{b}}$ & 0,68 \\
\hline Biri (Canna edulis) & Oval achatada & $43,06^{\mathrm{a}}$ & 1,73 & $59,61^{\mathrm{a}}$ & 2,76 & $16,55^{\mathrm{a}}$ & 0,99 \\
\hline Gengibre (Zingiber officinale) & Circular, oval achatada & $14,47^{\mathrm{f}}$ & 0,87 & $17,78^{\mathrm{d}}$ & 0,94 & $3,31^{\mathrm{d}}$ & 0,18 \\
\hline Mandioca (Manihot esculenta) & Circular & $14,39^{f}$ & 0,47 & $17,1^{\mathrm{de}}$ & 0,73 & $2,70^{\mathrm{d}}$ & 0,15 \\
\hline $\begin{array}{l}\text { Mandioquinha-salsa (Arracacia } \\
\text { xanthorrhiza) }\end{array}$ & Circular, poliédrica & $16,63^{\text {ef }}$ & 1,22 & $20,68^{\mathrm{d}}$ & 2,94 & $3,85^{\mathrm{d}}$ & 0,48 \\
\hline Taioba (Xanthosoma sp.) & Circular, poliédrica & $10,37^{g}$ & 0,21 & $12,87^{\mathrm{e}}$ & 0,15 & $2,50^{\mathrm{d}}$ & 0,13 \\
\hline Zedoária (Curcuma zedoaria) & Triangular achatada & $21,05^{\mathrm{cd}}$ & 0,37 & $28,26^{\mathrm{c}}$ & 1,37 & $7,21^{\mathrm{c}}$ & 0,89 \\
\hline
\end{tabular}

*Os valores representam a média de quinhentas repetições. Médias seguidas de letras distintas na coluna não diferem entre si ao nível de $5 \%$ de signnificância.
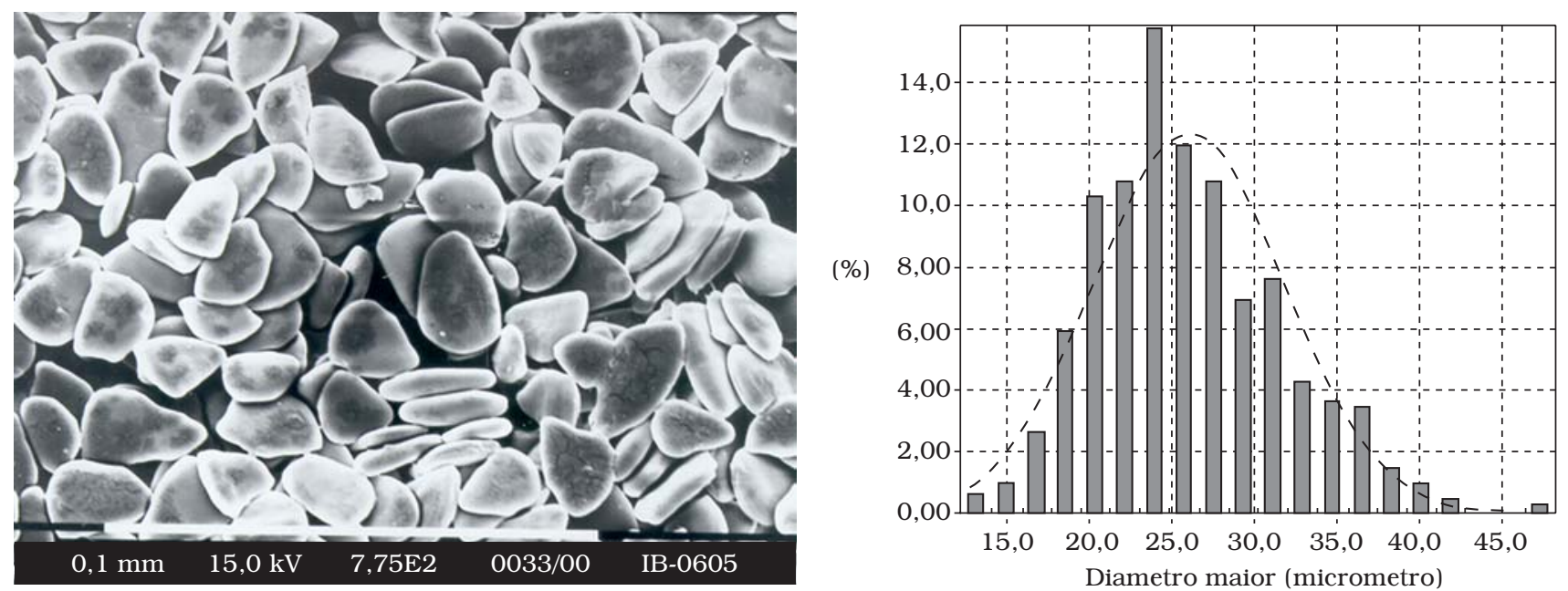

Figura 2. Fotomicrografia de grânulos de amido de açafrão e a distribuição de tamanho de grânulos (diâmetro maior em micrômetro).
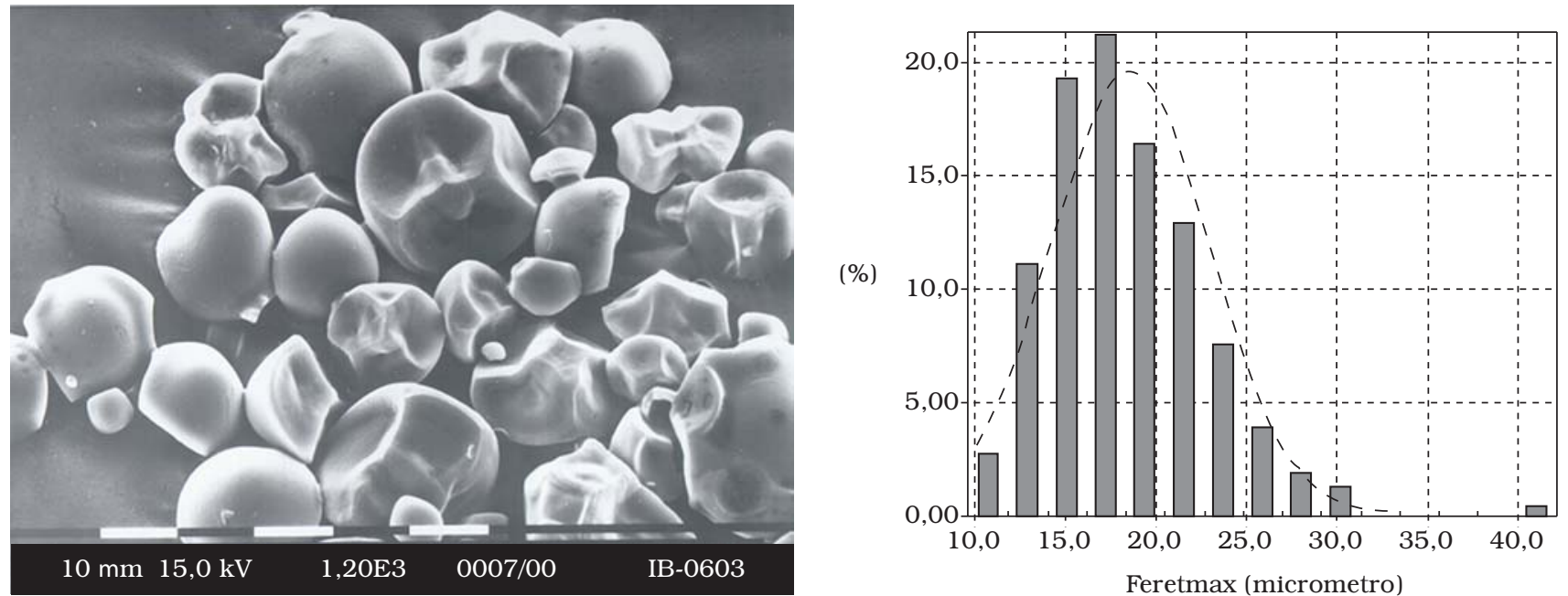

Figura 3. Fotomicrografia de grânulos de amido de ahipa e distribuição de tamanho (diâmetro maior em micrômetro).

de araruta mostrou distribuição homogênea, com grânulos de diferentes tamanhos e predomínio de grânulos na faixa de 20 a $40 \mu \mathrm{m}$ (Figura 4).
PÉREZ et al. ${ }^{23}$ relataram a forma de amidos de araruta, destacando pequena quantidade de grânulos circulares e um predomínio do formato de feijão. $\operatorname{ERDMAN}^{9}$ avaliou o tamanho 
dos grânulos através da microscopia eletrônica de varredura, encontrando diâmetro médio de $13 \mu \mathrm{m}$.

A análise de imagem mostrou grânulos de amido na batatadoce com formas circulares e poliédricas e, quanto ao tamanho, a distribuição mostrou grânulos de diferentes tamanhos com uma distribuição concentrada na faixa de 12 a $20 \mu \mathrm{m}$, evidenciando a forma de organização da planta que apresenta um câmbio central e vários câmbios periféricos, levando a menor heterogeneidade de tamanhos. O diâmetro maior máximo variou de 45 a $55 \mu \mathrm{m}$ e o diâmetro maior mínimo observado foi próximo a $10 \mu \mathrm{m}$ (Figura 5).

A faixa de tamanho (diâmetro maior) de maior freqüência foi próxima aos valores de $10-25 \mu \mathrm{m}$ citados por GALLANT et al. ${ }^{11}$ para amido de batata-doce. GARCIA e WALTER ${ }^{12}$ citam as formas redonda, oval e poligonal para grânulos de amido de batata-doce e tamanho variável de 2 a $42 \mu \mathrm{m}$.

A batata-doce ocupa o $6^{\circ}$ lugar entre as hortaliças mais plantadas no Brasil, correspondendo a uma produção anual de 500.000 toneladas, obtidas em uma área estimada de

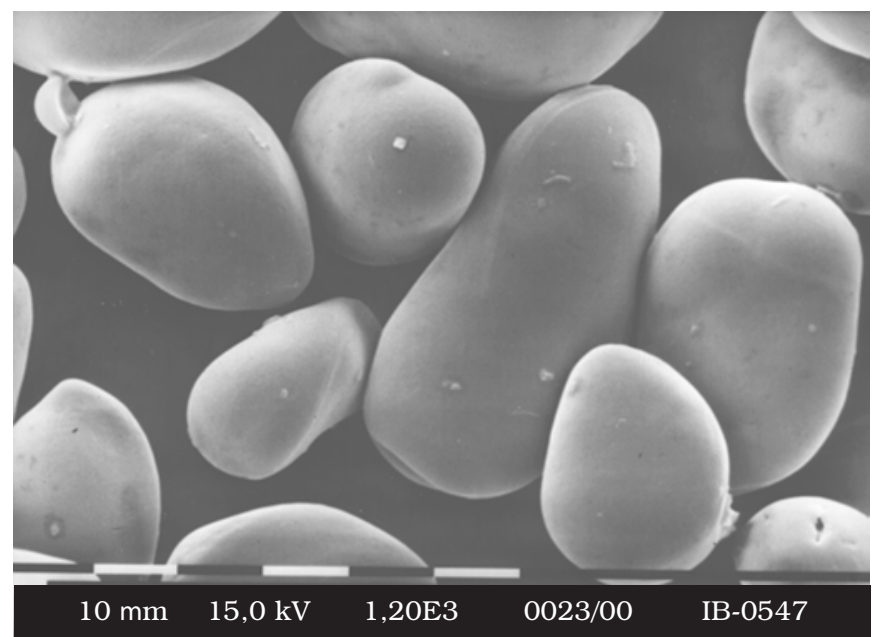

48.000 hectares. No Brasil, o investimento na cultura de batata-doce é muito baixo, e o principal argumento contrário ao investimento em tecnologia é que a lucratividade da cultura é baixa ${ }^{6}$. Contudo a possibilidade de processamento dessa tuberosa como fonte de amido pelas indústrias de amido de mandioca brasileiras contribuiria em muito para o avanço da cultura e para o mercado de amido.

A análise da forma e tamanho dos grânulos de amido de batata mostrou grânulos circulares e ovalados com predomínio de grânulos com diâmetro maior na faixa de 20 a $40 \mu \mathrm{m}$, apresentando uma faixa de distribuição de tamanho de 10 a $140 \mu \mathrm{m}$ (Figura 6).

Segundo ALEXANDER ${ }^{1}$, os grânulos de amido de batata apresentam formas oval e esférica com diâmetro variando de 5 a $100 \mu \mathrm{m}$ e diâmetro médio predominante de $27 \mu \mathrm{m}$.

A batata, tubérculo de origem andina, apresenta uma produção anual em torno de 307,9 milhões de toneladas, tendo como grandes produtores mundiais a China, Rússia, Índia e Estados Unidos, ocupando o Brasil a $19^{a}$ posição. A cultura

Figura 4. Fotomicrografia de grânulos de amido de araruta e distribuição de tamanho (diâmetro maior em micrômetro).
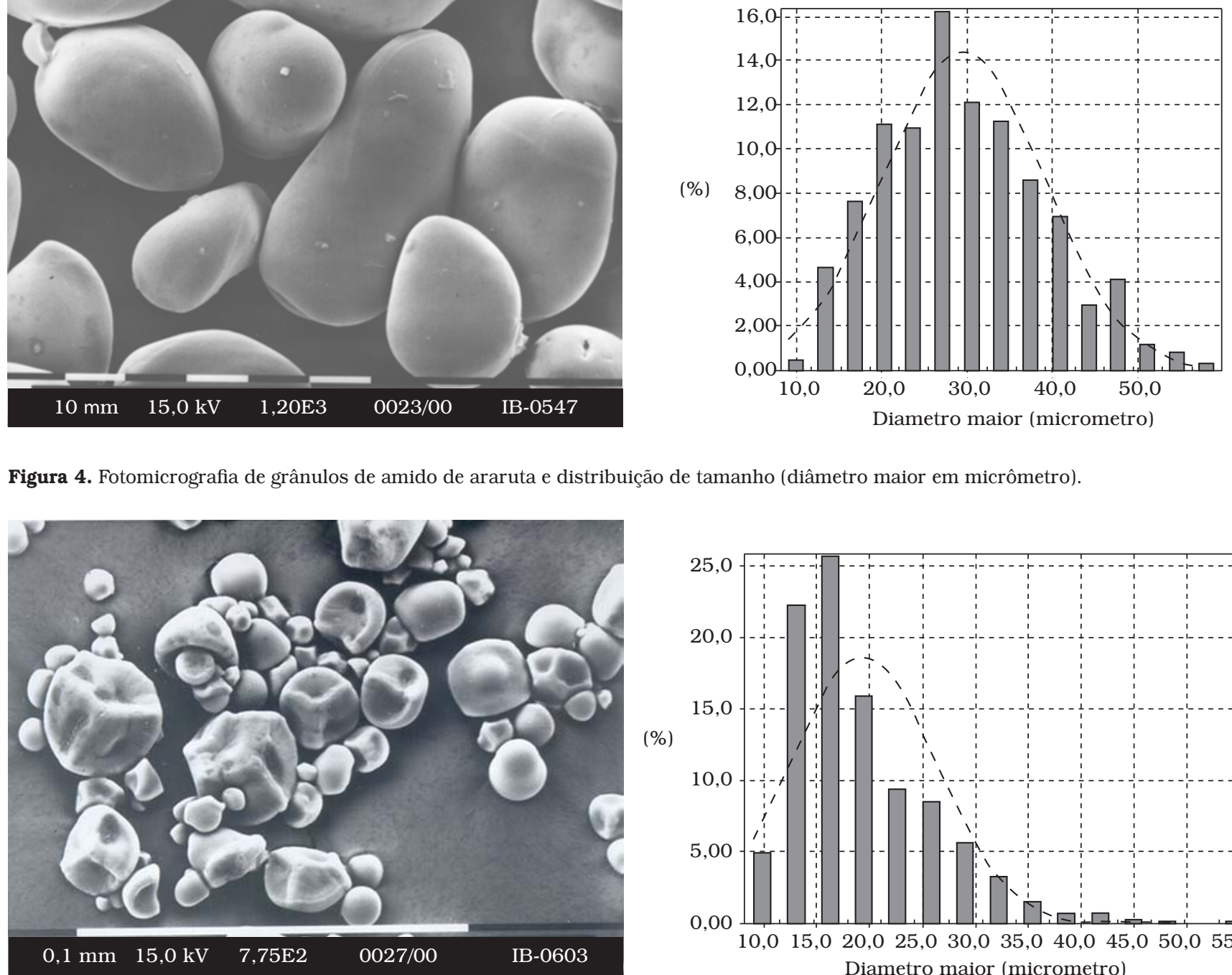

(\%)

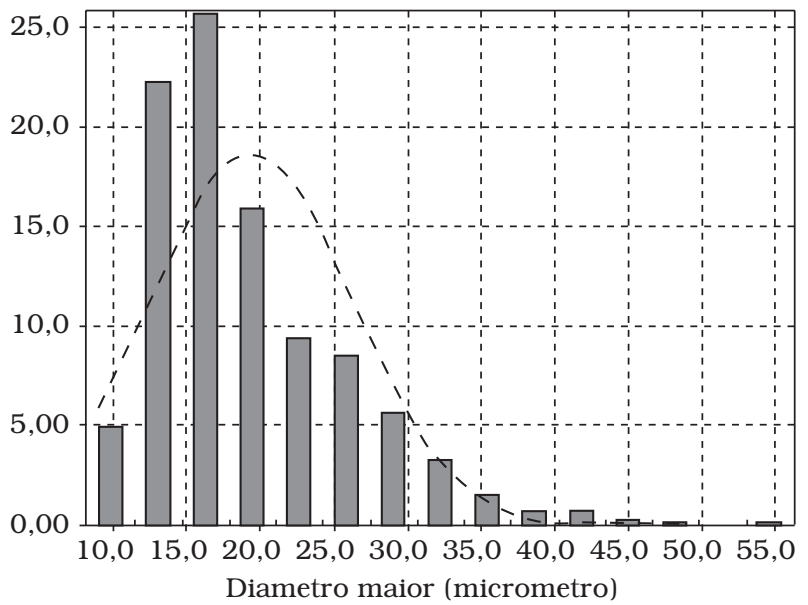

Figura 5. Fotomicrografia de grânulos de amido de batata-doce e distribuição de tamanho (diâmetro maior em micrômetro). 
da batata representa um importante gerador de divisas para o agronegócio brasileiro com uma produção de 3 milhões de toneladas, com os estados de Minas Gerais (37\%), São Paulo (30\%) e Paraná (22\%) responsáveis por $89 \%$ da produção nacional ${ }^{4}$.

No Brasil, o consumo de batata é essencialmente in natura com o setor de processamento na forma de chips, palito e batata palha em crescimento nos últimos anos. A fécula de batata comercializada no País é importada e empacotada aqui.

A análise de imagem dos grânulos de amido de biri mostrou grânulos ovais, grandes, de fácil observação em pequenos aumentos. A distribuição de tamanhos mostrou grande variação nos tamanhos de grânulos com predomínio na faixa de 40 a $80 \mu \mathrm{m}$. O diâmetro maior máximo observado foi de $110 \mu \mathrm{m}$. Devido à forma ovalada, a diferença média de diâmetros foi bastante grande $(16,55 \mu \mathrm{m})$ (Figura 7). Grânulos grandes facilitam o processo de extração de amido, pois decantam rapidamente.

SANTACRUZ et al. ${ }^{25}$, analisando a forma e tamanho de amidos de biri em microscopia eletrônica de varredura, observaram uma predominância do formato oval e tamanho variável de 35 a $101 \mu \mathrm{m}$, resultados concordantes com os observados neste trabalho.

A análise microscópica dos grânulos de amido de gengibre mostrou a forma circular e ovalada e uma distribuição de tamanhos bastante homogênea, com predomínio de diâmetro maior médio na faixa de 15 a $20 \mu \mathrm{m}$ (Figura 8).

O gengibre é uma especiaria mundialmente conhecida, sendo comercializada na forma fresca, em conserva ou em pó, sendo esta última responsável pelo maior volume de comércio internacional. Os principais produtos do gengibre são os óleos essenciais e a oleoresina, utilizados pela indústria de alimentos como ingredientes. O gengibre brasileiro é comercializado no estado fresco e se destina principalmente à exportação (70 a $80 \%$ ), portanto, 20 a $30 \%$ são perdidos no beneficiamento ${ }^{22}$. Uma possibilidade de se agregar valor aos rizomas remanescentes e também de um possível aproveitamento do resíduo gerado no processo de extração dos óleos essenciais do gengibre seria a extração da fécula de gengibre.

A observação dos grânulos de amido de mandioca mostrou grânulos circulares e alguns côncavo-convexos característicos.
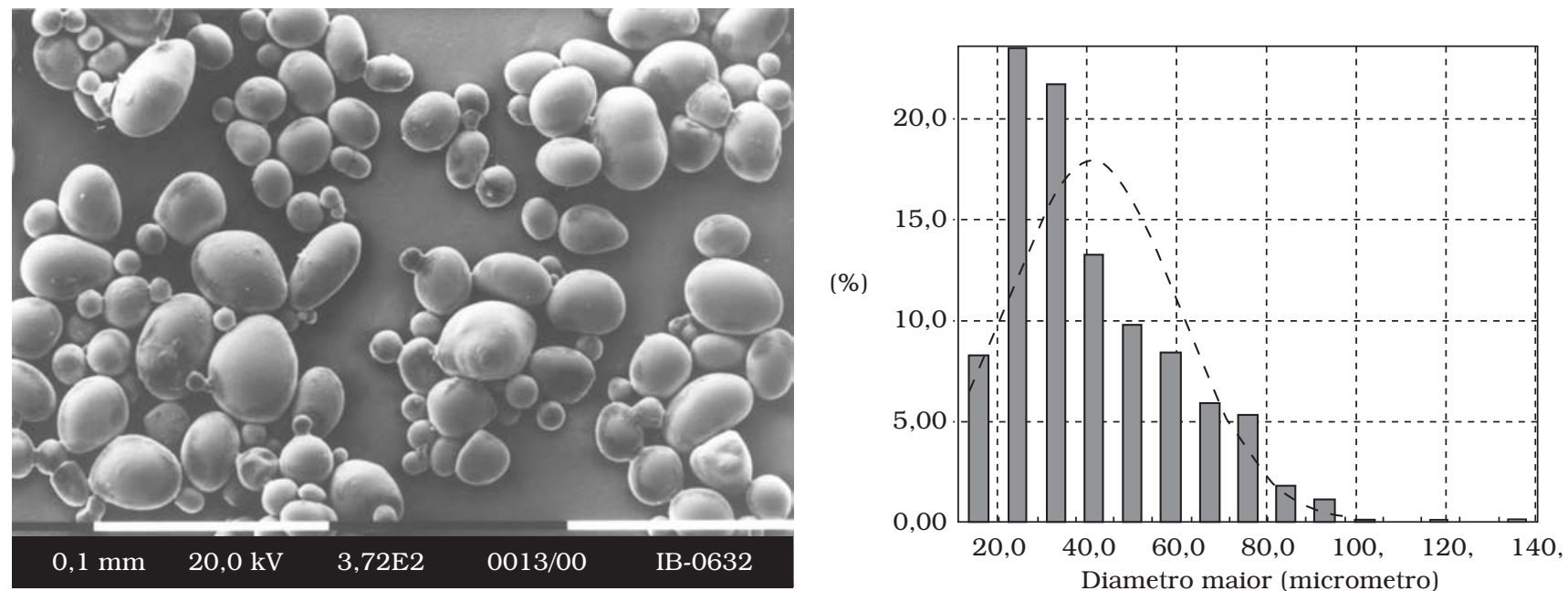

Figura 6. Fotomicrografia de grânulos de amido de batata e distribuição de tamanho (diâmetro maior em micrômetro).
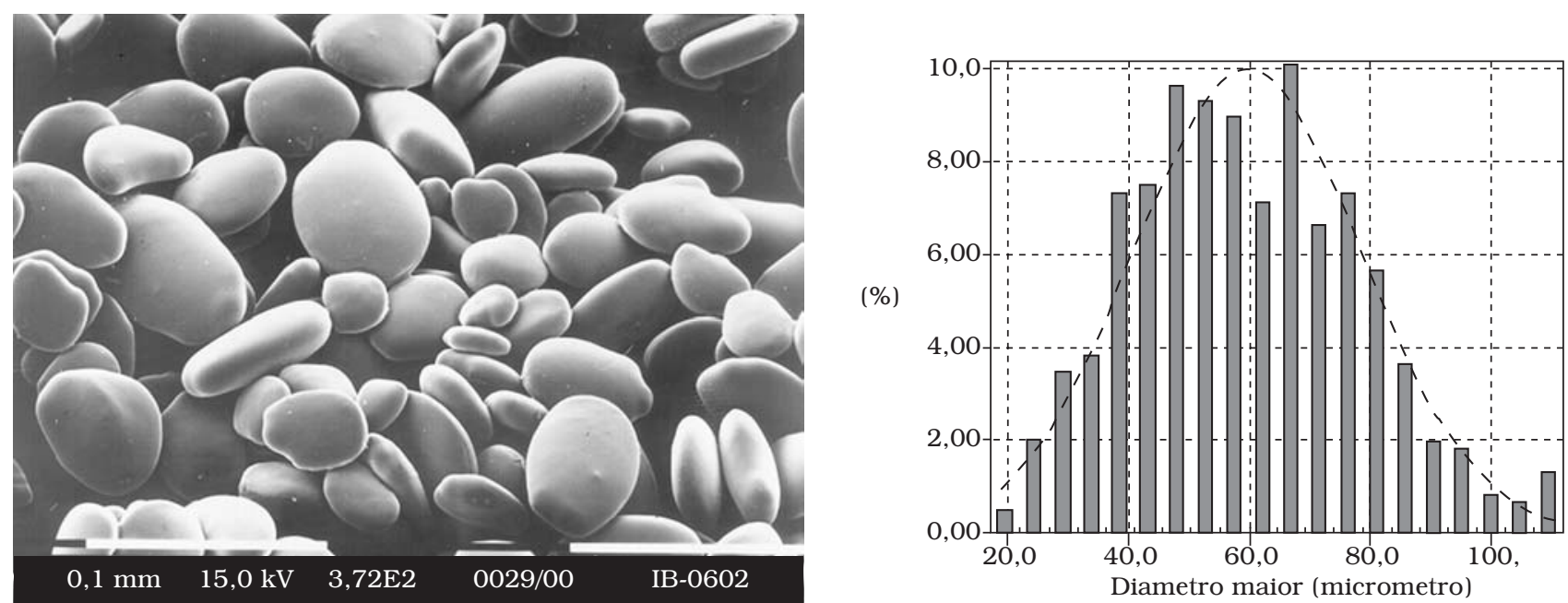

Figura 7. Fotomicrografia de grânulos de amido de biri e distribuição de tamanho (diâmetro maior em micrômetro). 
A distribuição de tamanho mostrou grânulos de diferentes tamanhos, o que já era esperado devido ao processo de tuberização da raiz a partir de um câmbio central. A distribuição foi normal com predomínio de grânulos com diâmetro maior entre 15 e $20 \mu \mathrm{m}$ (Figura 9).

Segundo RICKARD et al. ${ }^{24}$, as formas encontradas para o amido de mandioca são redonda, oval, truncada, poligonal e cilíndrica. Quanto ao tamanho, DEFLOOR et al. ${ }^{8}$ citam diâmetros variáveis de 3 a $32 \mu \mathrm{m}$.

A indústria alimentícia é a principal consumidora de amido no Brasil (68\% da produção), seguida pela indústria de papel (16\%), mineração (6\%) e têxtil (5\%). Considerando-se uma produção anual de amido no Brasil da ordem de 1,5 milhões de toneladas e a produção de fécula de mandioca de 546,5 milhões de toneladas, conclui-se que ela participa com $36,4 \%$ do mercado brasileiro de amido ${ }^{27}$.

A análise do amido de mandioquinha-salsa mostrou grânulos com forma circular predominantemente e alguns poliédricos. Quanto à distribuição de tamanho dos grânulos, observaram-se grânulos de diferentes tamanhos (7 a $45 \mu \mathrm{m}$ )

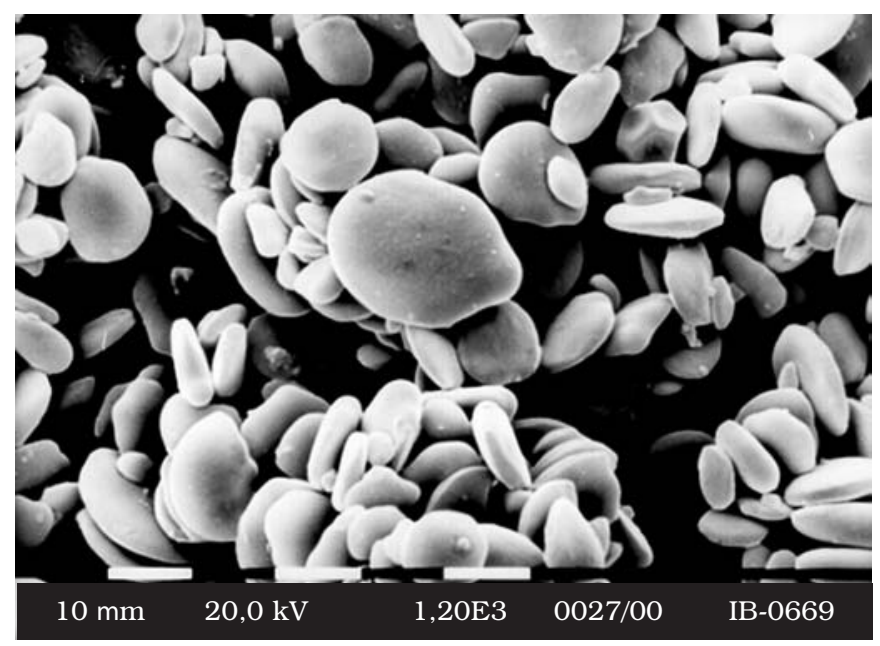

com predomínio de grânulos na faixa de 15 a $25 \mu \mathrm{m}$ de diâmetro maior (Figura 10). KIBUUKA e MAZZARI ${ }^{15}$ observaram a forma arredondada e diâmetro de 5 a $27 \mu \mathrm{m}$ para grânulos de amido de mandioquinha.

SANTACRUZ et al. ${ }^{25}$, analisando a forma e tamanho de grânulos de amido de mandioquinha-salsa em microscopia eletrônica de varredura, observaram forma irregular e diâmetro variável de 7 a $23 \mu \mathrm{m}$.

A mandioquinha-salsa no Brasil é uma hortaliça que apresenta considerável importância, com volume de comercialização em torno de 90.000 toneladas por ano e valor ao redor de 50 milhões de dólares ${ }^{3}$. É consumida diretamente ou utilizada pelas indústrias alimentícias no preparo de pratos prontos.

Os grânulos de amido de taioba apresentaram formas circular e poliédrica com diâmetro variável de 5 a $25 \mu \mathrm{m}$, com uma maior concentração de grânulos com 10 a $15 \mu \mathrm{m}$ de diâmetro maior (Figura 11). Estes dados estão em acordo com os observados por DEANG e DEL ROSÁRIO ${ }^{7}$ que citam a forma circular e diâmetro de 6-24 $\mu \mathrm{m}$ para grânulos de amido de taioba.

(\%)

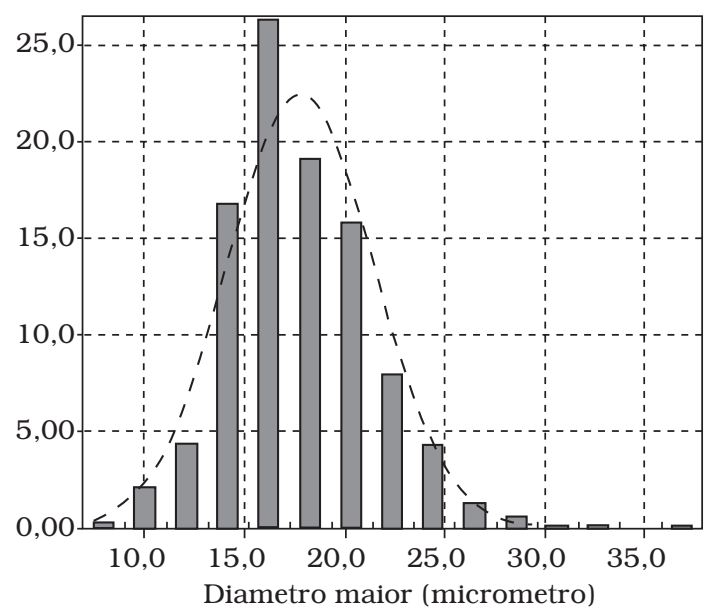

Figura 8. Fotomicrografia de grânulos de amido de gengibre e distribuição de tamanho (diâmetro maior em micrômetro).

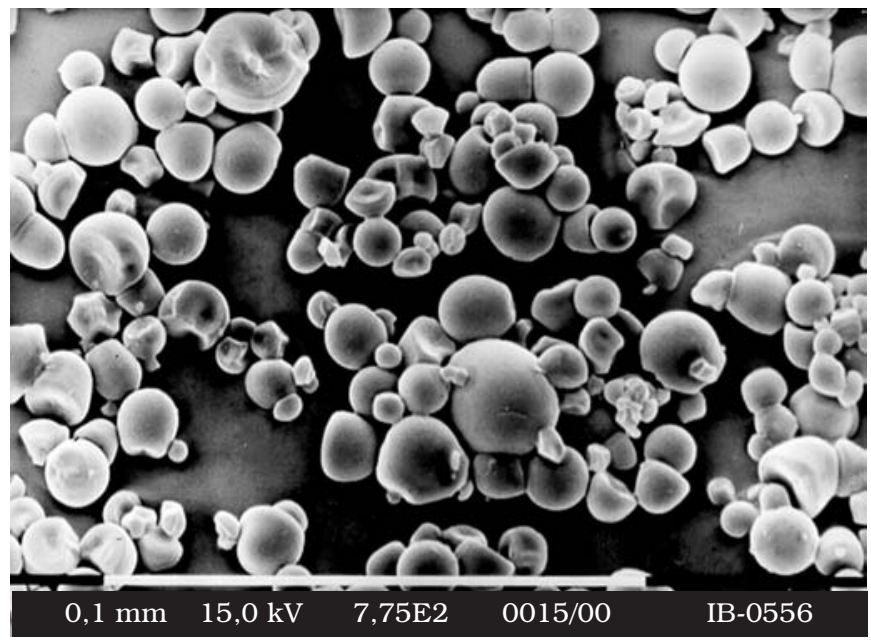

$(\%)$

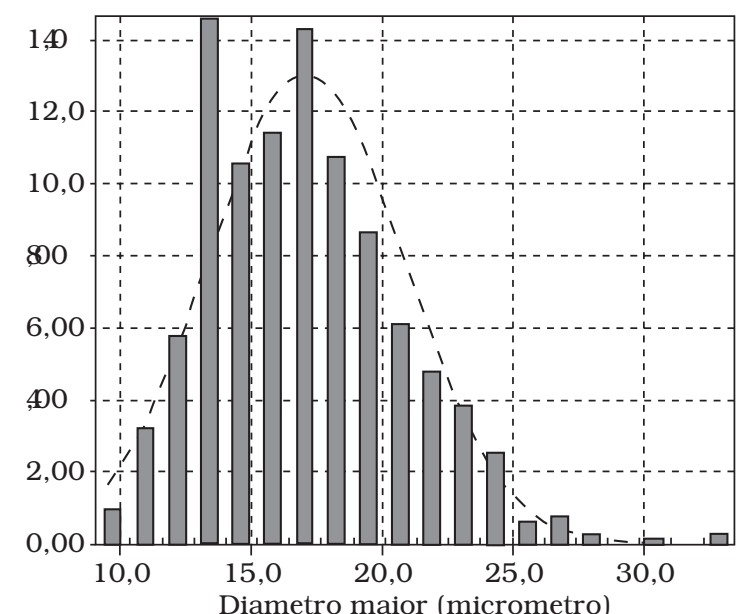

Figura 9. Fotomicrografia de grânulos de amido de mandioca e distribuição de tamanho (diâmetro maior em micrômetro). 


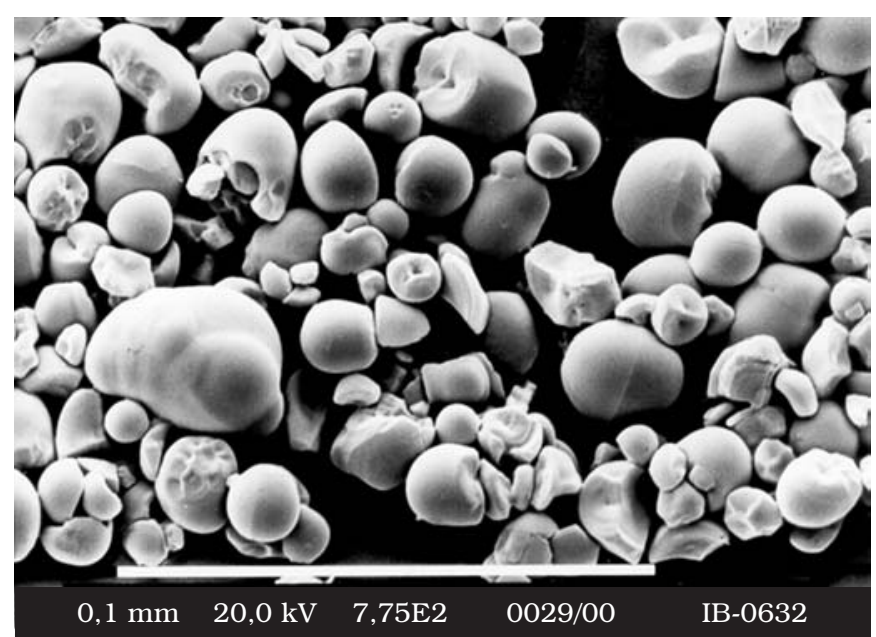

(\%)

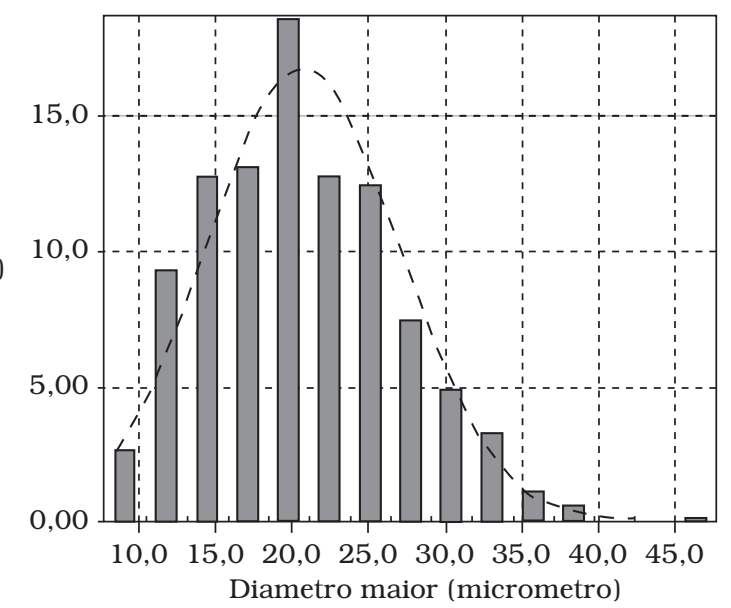

Figura 10. Fotomicrografia de grânulos de amido de mandioquinha-salsa e distribuição de tamanho (diâmetro maior em micrômetro).
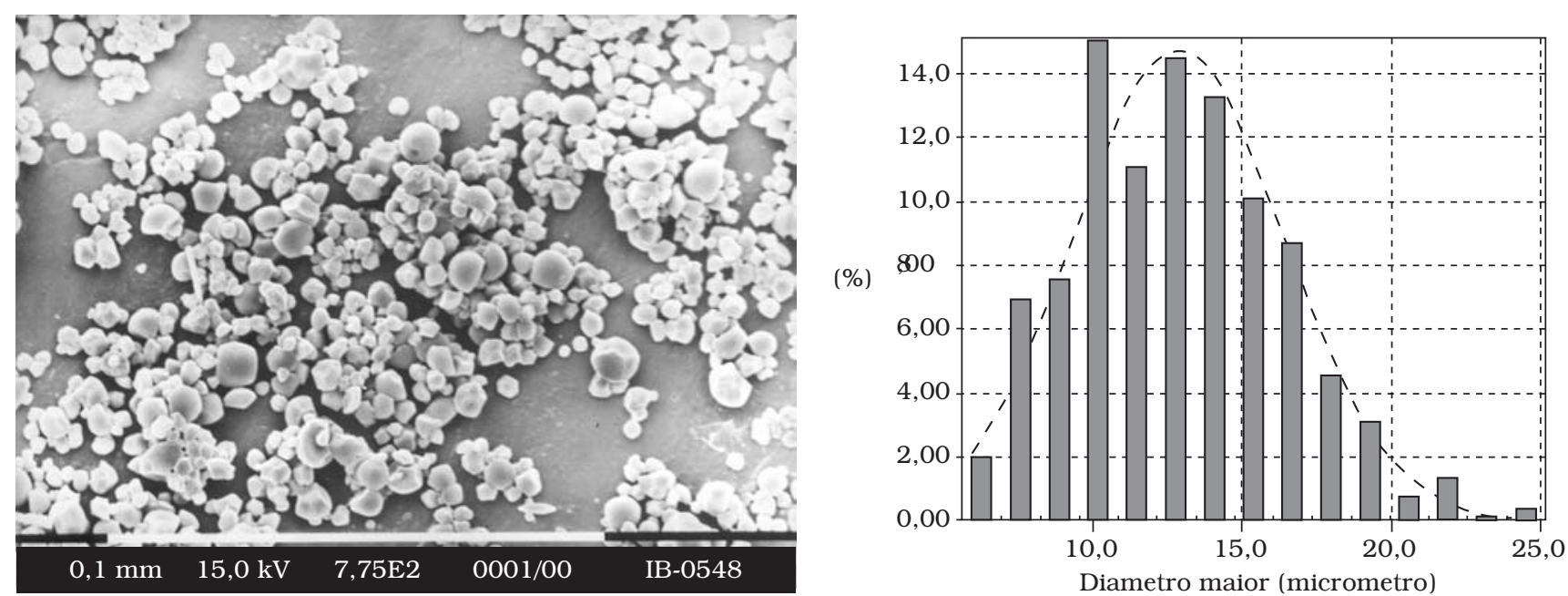

Figura 11. Fotomicrografia de grânulos de amido de taioba e distribuição de tamanho (diâmetro maior em micrômetro).

A taioba tem sido cultivada por pequenos produtores, visando principalmente à produção de folhas para consumo em pratos típicos ou ração animal. Os rizomas são consumidos cozidos. Apresenta elevada produtividade agrícola (30 toneladas por hectare), o que, aliado ao teor de amido (80\% da matéria seca), possibilitaria o processamento dessa tuberosa como matéria-prima amilácea.

A zedoária é um rizoma bastante utilizado como planta medicinal, mas com considerável teor de amido, o qual poderia ser utilizado como co-produto da obtenção dos óleos essenciais. A análise microscópica do amido de zedoária mostrou grânulos semelhantes aos de açafrão, com forma triangular predominantemente e alguns grânulos ovais. A distribuição de tamanho de grânulos mostra uma porcentagem significativa de grânulos de 25-30 $\mu \mathrm{m}$, com a presença de grânulos grandes (>90 $\mu \mathrm{m})$, mas em mínima porcentagem (Figura 12).

\section{Conclusões}

A partir dos resultados obtidos foi possível concluir que:
- Das fontes botânicas estudadas, os grânulos de amido com menor tamanho (diâmetro maior médio) são os de taioba (Xanthosoma sp) e os de maior tamanho os de biri (Canna edulis);

- A distribuição de tamanho de grânulos mais homogênea é a do amido de ahipa; e

- Os amidos com baixa diferença entre diâmetros e distribuição mais homogênea como os de ahipa, batata-doce e gengibre podem ser estudados para aplicação em papel.

\section{Referências bibliográficas}

1. ALEXANDER, R. J. Potato starch: new prospects for an old product. Cereal Foods World, v. 40, n. 1010, p. 763-764, 1995.

2. BECHTEL, D. B. et al. Size-distribution of weath starch granules during endosperm development. Cereal Chemistry, v. 67, n. 1, p. 59-63, 1990.

3. CÃMARA, F. L. A.; SANTOS, F. S. Cultura da mandioquinha-salsa. In: CEREDA, M. P. (coord). Agricultura: tuberoses amiláceas 

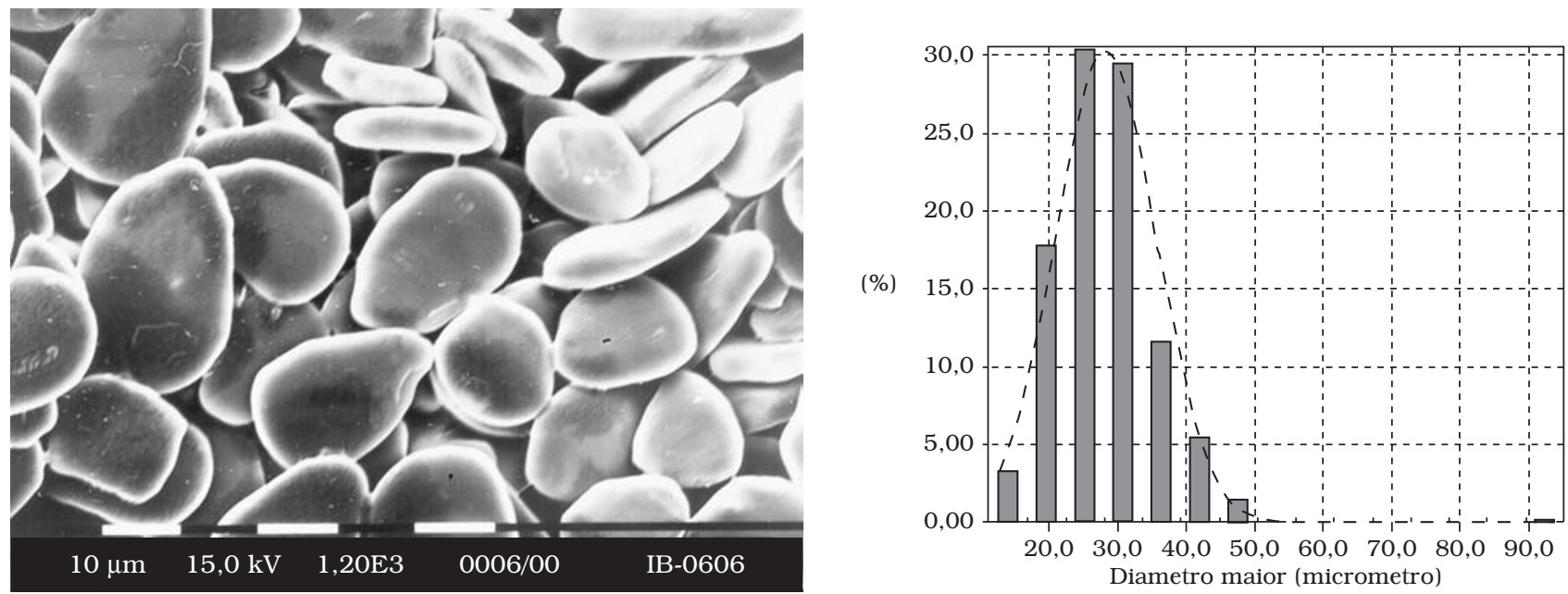

Figura 12. Fotomicrografia de grânulos de amido de zedoária e distribuição de tamanho (diâmetro maior em micrômetro).

latino americanas. São Paulo: Fundação Cargill, p. 519-532, 2002.

4. CAMARGO FILHO, W. P.; ALVES, H. S. Mercado de batata no Brasil: análise de produção, importação e preços. Informações Econômicas, v. 35, n. 5, p. 71-76, 2005.

5. CAMPBELL, M. R. et al. Variation of starch granule size in tropical maize germ plasm. Cereal Chemistry, v. 73 , n. 5, p. 536-538, 1996.

6. Da SILVA, J. B. C.; LOPES, C. A.; MAGALHÃES, J. S. Cultura da batata doce. In: CEREDA, M. P. (coord). Agricultura: tuberoses amiláceas latino americanas. São Paulo: Fundação Cargill, p. 448-504, 2002

7. DEANG, L. M.; DEL ROSARIO, R. R. Physicochemical characteristics of starches from some rootcrops. The Philippine Agriculturist, v. 76, n. 4, p. 443-455, 1993.

8. DEFLOOR, I.; DEHING, I.; DELCOUR, J. A. Physico-chemical properties of cassava starch. Starch/Stärke, v. 50, n. 2-3, p. 58-64, 1998.

9. ERDMAN, M. D. Starch form arrowroot (Maranta arundinacea) grown at Titon, Georgia. Cereal Chemistry, v. 63, n. 3, p. 277-279, 1986.

10. FORSTHY, J. L. et al. Characterization of starch from tubers of yam bean (Pachyrhizus ahipa). Journal of Agricultural and Food Chemistry, v. 50, n. 2, p. 361-367, 2002.

11. GALLANT, D. J. et al. On ultrastructural and nutritional aspects of some tropical tuber starches. Starch/Stärke, v. 34, n. 8, p. 255-262, 1982.

12. GARCIA, A. M.; WALTER, W. M. Physicochemical characterization of starch from Peruvian sweet potato selections. Starch/Stärke, v. 50, n. 88, p. $331-337,1998$.

13. GOERING, K. J.; DE HAAS, B. New starches. VIII. Properties of the small granule starch from Colocasia esculenta. Cereal Chemistry, v. 49, n. 6, p. 712-719, 1972.

14. HE, X. G. et al. Liquid chromatography-electrospray mass spectrometric analysis of curcuminoids and sesquiterpenoids in turmeric (Curcuma longa). Journal of Chromatography, v. 818, n. 1, p. 127-132, 1998.

15. KIBUUKA, G. K.; MAZZARI, M. R. Isolamento, caracterização físico-química e perspectivas industriais de amido de batata baroa (Arracacia xanthorhyza Bancroft Syn). In: XXI Congresso Brasileiro de Olericultura, Campinas, SP, p. 34, 1981.

16. LEONEL, M. et al. Extração e caracterização do amido de Biri (Canna edulis). Brazilian Journal of Food Technology, Campinas, v. 5, n. 77, p. 27-32, 2001.

17. LEONEL, M.; CEREDA, M. P; SARMENTO, S. B. S. Processamento de araruta (Maranta arundinacea) para extração e caracterização da fração amilácea. Brazilian Journal of Food Technology, Campinas, v. 5, n. 93, p. 151-155, 2002.

18. MADSEN, M. H.; CHRISTENSEN, D. H. Changes in viscosity properties of potato starch during growth. Starch/Stärke, v. 48, n. 7-8, p. 245-249, 1996.

19. MILANEZ, C. R. D. Morpho-anatomical characterization of vegetative organs of Pachyrhizus ahipa (Wedd.) Parodi (Fabaceae). 2002. 116 p. (Master in Biological Science)- Instituto de Biociências, Botucatu, 2002.

20. MONTEIRO, D. A.; PERESSIN, W. A. Cultura da araruta. In: CEREDA, M. P. (coord). Agricultura: tuberoses amiláceas latino americanas. São Paulo: Fundação Cargill, p.440-447, 2002.

21. NODA, T., TAKAHATA, Y., NAGATA, T. Properties of sweet potato starches from different tissue zones. Starch/Stärke, v. 44, n. 10, p. 365-368, 1992.

22. NOGUEIRA, E. A.; MELLO, N. T. C. Um caso bem sucedido: a produção familiar de gengibre em Tapiraí, Estado de São Paulo. Informações econômicas, v. 31, n.10, p. 53-59, 2001.

23. PÉREZ, E.; LARES, M.; GONZÁLEZ, Z. Some characteristics of sagu (Canna edulis) and zulu (Maranta sp) rhizomes. Journal of Agricultural and Food Chemistry, v. 45, n. 7, p. 2546-2549, 1997.

24. RICKARD, J. E.; ASAOKA, M.; BLANSHARD, J. M. V. The physicochemical properties of cassava starch. Tropical Science, v. 31, n. 22, p. 189-207, 1991.

25. SANTACRUZ, S. et al. Physicochemical characterizations of three unconventional sources of starch from the Andean region in Ecuador. Tropical Agriculture, v. 75, n. 2, p. 302-304, 1998.

26. SATIN, M. Functional properties of starches. In: International Symposium on Tropical Root and Tuber Crops, Thiruvananthapuran (Trivandrum), 2000. 
27. SILVA, J. R.; ASSUMPÇÃO, R.; VEGRO, C. L. R. A inserção da fécula de mandioca no mercado de amido. Informações econômicas, v. 30 , n. 7 , p. $31-41,2000$.

28. SINGH, J.; SINGH, N. Studies on the morphological, thermal and rheological properties of starch separated from some Indian potato cultivars. Food Chemistry, v. 75, n. 1, p. 67-77, 2001.

29. SRIROTH, K. et al., Cassava starch granule structure-function properties: influence of time and conditions at harvest on four cultivars of cassava starch. Carbohydrate Polymers, v. 38, n. 2, p. 161-170, 1999.
30. VIGNEAU, E. et al. Number of particles for the determination of size distribution from microscopic images. Powder Technology, v. 107 , n. 3, p. 243-250, 2000.

31. VASANTHAN, T.; SOSULSKI, F. W.; HOOVER, R. The reactivity of native and autoclaved starches from different origins towards acetylation and cationization. Starch/Stärke, v. 47, n. 4, p. 135-143, 1995. 